\title{
The Cardica C-Port System: Clinical and angiographic evaluation of a new device for automated, compliant distal anastomoses in coronary artery bypass grafting surgery-A multicenter prospective clinical trial
}

\author{
Klaus E. Matschke, MD, ${ }^{\text {a }}$ Jan F. Gummert, MD, ${ }^{\mathrm{b}}$ Stefanos Demertzis, MD, ${ }^{\mathrm{c}}$ Utz Kappert, MD, ${ }^{\text {a }}$ Marcel B. Anssar, MD, ${ }^{\mathrm{d}}$ \\ Francesco Siclari, MD, ${ }^{c}$ Volkmar Falk, MD, ${ }^{b}$ Edwin L. Alderman, MD, ${ }^{e}$ Christian Detter, MD, ${ }^{f}$ \\ Hermann Reichenspurner, MD, and Wolfgang Harringer, $\mathrm{MD}^{\mathrm{d}}$
}

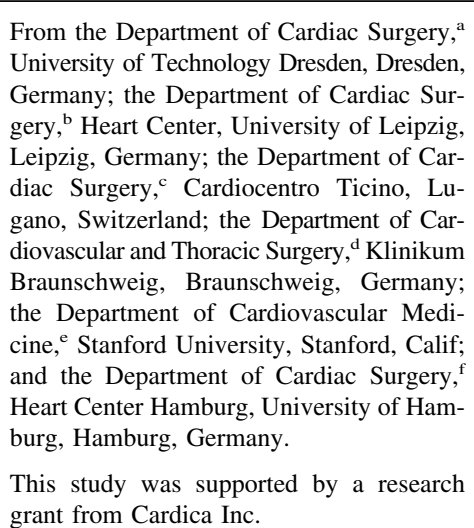

Read at the Eighty-fifth Annual Meeting of The American Association for Thoracic Surgery, San Francisco, Calif, April 10-13, 2005.

Received for publication March 31, 2005; revisions received Aug 10, 2005; accepted for publication Aug 17, 2005

Address for reprints: Klaus E. Matschke, MD, Department of Cardiac Surgery, Heart Center Dresden University Hospital, Fetscherstr 76, D-01307 Dresden, Germany (E-mail: k.matschke@herzzentrumdresden.com).

J Thorac Cardiovasc Surg 2005;130:1645-52 $0022-5223 / \$ 30.00$

Copyright (C) 2005 by The American Association for Thoracic Surgery

doi:10.1016/j.jtcvs.2005.08.033
Objectives: The C-Port System (Cardica, Inc, Redwood City, Calif) integrates in one tool all functions necessary to enable rapid automated distal coronary anastomoses. The goal of this prospective, nonrandomized, and multicenter study is to determine the safety and efficacy of this novel anastomotic system.

Methods: Five centers enrolled 133 patients awaiting elective coronary artery bypass grafting surgery. Outcome variables were intraoperative device performance, incidence of device-related adverse events, predischarge and 6-month angiographic graft patency, and 12-month clinical outcome. Independent core laboratories performed qualitative and quantitative angiographic and computed tomographic assessments.

Results: The C-Port was used to perform a vein-to-coronary anastomosis in 130 patients. Intraoperative conversion to a hand-sewn anastomosis was necessary in 11 patients because of inadequate target site preparation, inappropriate target vessel selection, or both. Inadequate blood flow related to poor runoff required conversion in 3 additional patients. Three patients died before discharge of causes unrelated to the device. At discharge, 113 patients had a C-Port implant in place, and 104 C-Port anastomoses were studied by means of angiography, resulting in 100 FitzGibbon A, 3 FitzGibbon B, and 1 FitzGibbon 0 classifications. At 6 months, one additional patient died of a device-unrelated cause, and 98 patients were evaluated by means of angiography $(\mathrm{n}=89)$. Overall patency (FitzGibbon A) was $92.1 \%$. Three C-Port anastomoses were rated FitzGibbon B, and 4 were rated FitzGibbon 0. At 12 months, 107 (98.2\%) of 109 alive patients were followed up, without any reports of device-related major adverse cardiac events.

Conclusions: The C-Port System allows for a rapid, reliable, and compliant distal anastomosis and yields favorable 6-month angiographic and 12-month clinical results when compared with published studies.

I n coronary artery bypass grafting (CABG) hand-sewn anastomoses are considered the gold standard. These are performed with either a running or an interrupted suture technique. ${ }^{1}$ In the era of surgical intervention with conventional sternotomy and an arrested heart, these suturing techniques yield excellent results, despite being time-consuming, difficult to perform in a confined space, and associated with a significant learning curve. The introduction of less invasive surgical approaches and beating-heart surgery has triggered an interest in the development of anastomotic devices. These devices are intended to enable rapid, precise, and reliable anastomoses to further enhance minimally invasive coronary bypass surgery. ${ }^{2}$ 


\author{
Abbreviations and Acronyms \\ $\mathrm{CABG}=$ coronary artery bypass grafting \\ $\mathrm{CT}=$ computed tomography \\ ECG = electrocardiography \\ MACE $=$ major adverse cardiac event \\ NYHA $=$ New York Heart Association
}

Recently, the Cardica C-Port Anastomotic System (Cardica, Inc, Redwood City, Calif) has been introduced to facilitate saphenous venous graft-to-coronary artery anastomoses. The C-Port System allows rapid automated distal coronary anastomoses by integrating all the functions necessary for completing an anastomosis. A compliant, angled, end-toside anastomosis is performed by automatically placing 8 individual clips and creating an arteriotomy with the push of a button.

This multicenter clinical trial investigated the safety and efficacy of the C-Port device in the construction of distal coronary anastomoses.

\section{Materials and Methods}

After obtaining local ethics committee approval and informed patient consent, this study was performed as a prospective, nonrandomized clinical trial in patients referred to the investigators for multivessel CABG.

Study inclusion criteria were age greater than 18 years and less than 85 years, ejection fraction of greater than $30 \%$, creatinine value of less than $200 \mathrm{mmol} / \mathrm{L}$, and the requirement for nonemergency bypass of at least one coronary artery. Exclusion criteria were previous CABG surgery, the preoperative need for an intraaortic balloon counterpulsation, bleeding diathesis, a recent cerebrovascular accident, and patients in New York Heart Association (NYHA) class IV.

The study design included a perioperative assessment with predischarge angiography, intermediate patency evaluation at 6 months, and longer-term (12-month) clinical follow-up with resting and stress electrocardiography (ECG) and assessment of major adverse cardiac events (MACEs). A MACE was defined as the presence of death, myocardial infarction, or the need for target vessel revascularization.

\section{Anastomotic System}

The C-Port device (Figure 1) integrates in one tool all functions necessary to enable rapid automated distal coronary anastomoses. When using the Cardica C-Port System, a vein is harvested from the patient's leg by conventional means and is attached to the cartridge of the C-Port deployment device (Figure 2). The surgeon creates a small incision in the target vessel. The graft is then inserted between the 2 cartridge arms and attached by 4 small spikes. This system is suitable for coronary arteries as small as 1 $\mathrm{mm}$ in internal diameter. A small incision is created in the target vessel, and the anvil of the C-Port is inserted. The connection between the vein graft and the coronary artery can then be performed rapidly, without the need for temporary occlusion of the

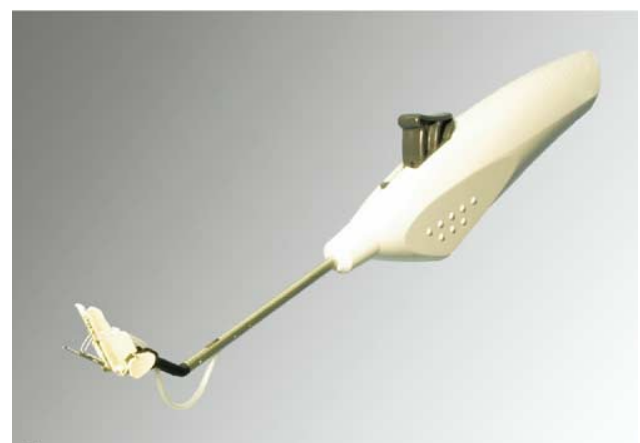

A

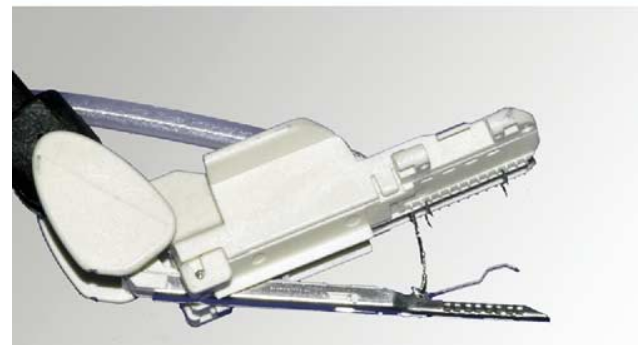

B

Figure 1. A, The Cardica C-Port System. B, Close-up view of the C-Port cartridge and anvil. The anvil is $1 \mathrm{~mm}$ in diameter and has incorporated an arteriotomy knife. The cartridge contains 8 clips.

target vessel. Deployment is accomplished by depressing a trigger button on the deployment handle, which first approximates the cartridge onto the coronary target and then deploys 8 individual stainless-steel anastomotic clips that penetrate the graft and target vessels and form against the anvil inside the coronary artery. Each clip has 4 tines that form in pairs for a total of 32 points of tissue approximation. A knife located within the anvil is deployed simultaneously and cuts the coronary artery from the inside out, thereby creating the arteriotomy. The cartridge then unclamps, and the device is removed from the anastomosis site through the previously created incision. A stitch is necessary in most instances to occlude the anvil insertion hole, and additional stitches might be necessary to provide hemostasis at the toe and heel (Figure 3).

In the present study clinically unsuccessful deployments were observed and caused by the inability of the cartridge to align with the anvil as a result of inadequate target site preparation. In these situations the surgeon removes the deployment devices and is confronted with an anvil insertion hole of approximately $1 \mathrm{~mm}$ and no attachment of the graft to the coronary vessel but also no further damage to the graft or target vessel. The surgeon must therefore only extend the anvil insertion hole to the desired length necessary for a hand-sewn anastomosis. In events in which the C-Port anastomosis was technically successful but the surgeon decided to convert to a hand-sewn anastomosis because of, for example, nonsatisfactory blood flow, the surgeon dissolved the anastomosis by pulling at the toe of the graft and thereby removing the staple attachments in a zipper-like fashion. With this type of traction, in 

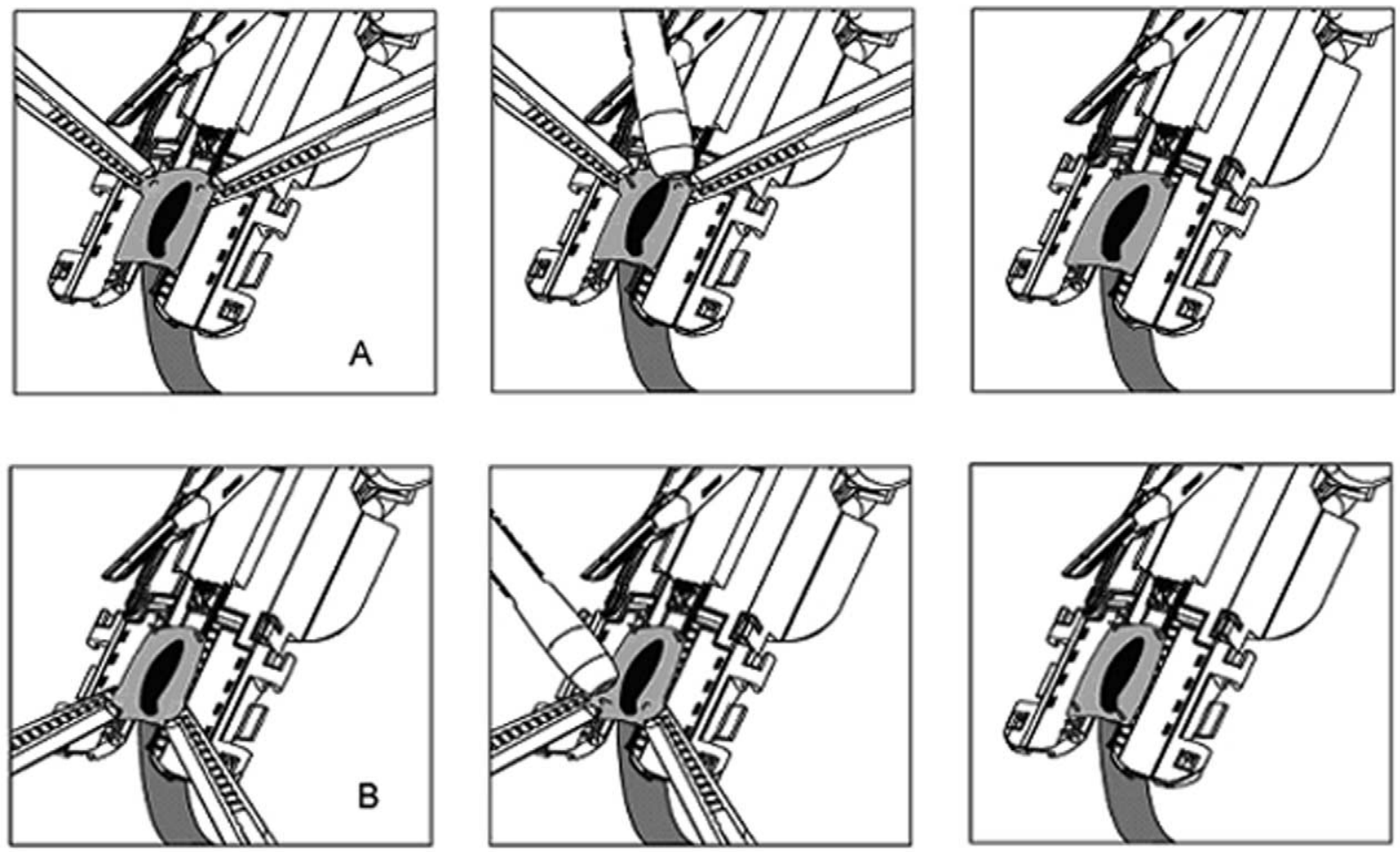

Figure 2. Main steps of loading the vein to the C-Port device at the toe (A) and the heel (B). The graft is incised on one side and inserted between the cartridge arms. The heel of the graft is then attached to 2 control spikes on the heel surface of the cartridge. The graft is then spread over the cartridge arms, and the toe of the graft is attached to the control spikes at the toe. The distal anastomosis can be done before or after the proximal anastomosis is completed.

most instances the staples unfold, leaving behind small points of penetration through the target vessel wall similar in size to those experienced after puncturing a target vessel wall with a 6-0 Prolene needle (Ethicon, Inc, Somerville, NJ). The staple penetrates the target vessel wall approximately $0.25 \mathrm{~mm}$ from the arteriotomy edge. Should the staple tear through the target vessel wall, a serrated target vessel wall edge is left behind that remains suitable for a hand-sewn anastomosis.

\section{Core Laboratory Analysis}

The patency of the index grafts was evaluated by means of either angiography or computed tomography (CT). The digital-film images were assessed by respective core laboratories. Assessment of angiographies and CT scans were performed at Stanford University Medical Center under the direction of Edwin Alderman (angiography) and Geoffrey Rubin (CT). For angiographic images, distal anastomosis patency was classified according to the FitzGibbon scoring system. ${ }^{3}$ C-Port anastomoses evaluated by means of CT were classified as patent if there was positive contrastation in the graft, including the distal anastomosis and target vessel. Because of the known limitations of CT, these data were excluded in the patency statistics.

The Core Angiographic Laboratory at Stanford used both qualitative and quantitative methods to evaluate each anastomosis.
Qualitative methods included estimates of thrombolysis in myocardial infarction flow grade and general assessments of patency. The quantitative coronary angiography laboratory included measurement of the internal lumen dimensions of the graft proximal to the distal anastomosis (A), the coronary target distal to the anastomosis (C), and the internal diameter of the anastomosis itself (B). This was performed by the core laboratory using standard angiographic computer software (PlusPlus; Sanders Data Systems, Stanford, Calif). These dimensions made it possible to calculate the average percentage diameter stenosis, as described by Caskey and associates $^{4}:(A+C) / 2-B /(A+C) / 2$. If there was a narrowing in the proximity of the anastomosis, such as the toe or heel of the anastomosis, the narrowest diameter was used as B in this formula. A mean negative anastomotic stenosis indicates that the anastomotic diameter exceeds that of the surrounding graft or coronary artery.

\section{Results}

The details of patient enrollment and follow-up can be derived from Figure 4. A total of 133 patients met preoperative and intraoperative inclusion and exclusion criteria. The patient demographics are described in Table 1.

C-Port deployments were attempted in 130 patients and were successful in 119 patients. Eleven deployments were 


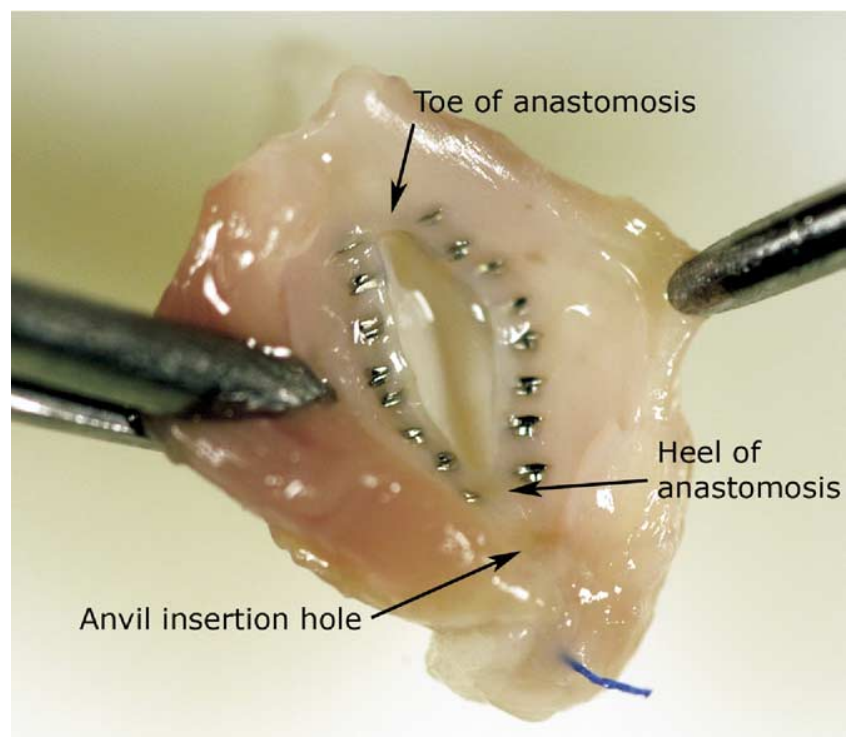

Figure 3. Intimal view of a dissected human coronary artery after in vitro deployment of the C-Port System. The C-Port System creates a compliant end-to-side anastomosis.

converted to hand-sewn anastomoses because of either inadequate tissue preparation of the target vessel or inappropriate target vessel selection, resulting in incomplete anastomoses. In 3 additional patients intraoperative graft blood was considered inadequate, and these C-Port anastomoses were converted to hand-sewn anastomoses. Subsequent blood flow measurements did not demonstrate an improvement, suggesting poor target vessel run-off. Three patients died before discharge of device-unrelated causes (right ventricular failure-extracorporeal membrane oxygenation $[\mathrm{n}=$ $1]$, adult respiratory distress syndrome $[\mathrm{n}=1]$, and perioperative myocardial infarct after hemorrhage and resuscitation $[n=1])$. In the patient with right ventricular failure, autopsy was performed, and patency of the C-Port was confirmed. Hemorrhage and myocardial infarction was related to a torn-off hand-sewn anastomosis. In this patient the C-Port anastomosis was found to be patent. At discharge, 113 patients had a C-Port implant in place. In these patients the C-Port device was placed as an end-to-side anastomosis in 108 single grafts, 4 single sequential grafts, and 1 double sequential graft. The diagonal coronary artery was grafted in $23 \%$, circumflex branches were grafted in $62 \%$, and the distal segment of the right coronary artery was grafted in $15 \%$. The average target vessel diameter was $1.6 \pm 0.4 \mathrm{~mm}$. Forty percent of all target vessels were less than or equal to $1.5 \mathrm{~mm}$ in internal diameter (core laboratory analysis). Extracorporeal circulation and cardioplegia was established in $96 \%$ of patients $(\mathrm{n}=109)$ during the construction of the device anastomosis. An additional stitch at the toe and heel was necessary in almost all deployments. The average in- traoperative blood flow was $41 \pm 25 \mathrm{~mL} / \mathrm{min}$. There were no redo operations for bleeding or revision of the C-Port anastomoses.

\section{Discharge Patency}

Of the $107 \mathrm{C}$-Port anastomoses studied by means of angiography $(\mathrm{n}=104)$ and $\mathrm{CT}(\mathrm{n}=3), 106$ anastomoses were found to be patent by the core laboratories, for a predischarge patency rate of $99 \%$ (106/107). In 3 patients the C-Port distal anastomosis was rated FitzGibbon B. The average distal anastomosis stenosis was $-26.4 \% \pm 31.8 \%$. The overall freedom of stenosis greater than $50 \%$ (FitzGibbon A) at discharge for grafts evaluated by means of angiography was therefore $96.2 \%$ (100/104).

\section{Six-month Follow-up}

Of the 113 patients discharged, one patient died 5 months postoperatively of lung cancer, 6 patients voluntarily withdrew, and 1 patient was unable to return because of illness. Therefore at 6 months, 105 patients returned for clinical follow-up (93.8\% [105/112]); 98\% were in Canadian Cardiovascular Society class 0 or 1, and $99 \%$ were in NYHA class I or II. None of the patients had a myocardial infarction or target vessel revascularization associated with an index graft since discharge (MACE $=0$ ).

Of these patients, 98 (87.5\% [98/112]) were evaluated by means of angiography $(\mathrm{n}=89)$ or CT $(\mathrm{n}=9)$. The results indicated that $85 \mathrm{C}$-Port index grafts evaluated by means of angiography and all $9 \mathrm{C}$-Port index grafts evaluated by means of CT were patent, for a rate of $95.9 \%$ (94/98). Three C-Port index grafts evaluated by means of angiography were rated FitzGibbon B, and 4 were rated FitzGibbon 0. Excluding the 4 occluded anastomoses, the average distal anastomosis stenosis was $-10.7 \% \pm 30.3 \%$, with a minimum of $-116 \%$ and a maximum of $71 \%$. The overall freedom of stenosis greater than 50\% (FitzGibbon A) in grafts evaluated by means of angiography at 6 months was therefore $92.1 \%$ (82/89). In the core laboratory analysis there was no evidence of any narrowing of the coronary artery at the site of the anvil insertion hole.

\section{Twelve-month Follow-up}

At 12 months postoperatively, 3 additional patients had died of causes unrelated to the C-Port anastomosis (renal failure, cerebral tumor, and recurrent strokes), and 107 implanted patients returned, for a compliance rate of 98.2\% (107/109). Of these patients, $93 \%$ were in Canadian Cardiovascular Society class 0 or I, and $98 \%$ were in NYHA class II or I. None of the patients had a recent myocardial infarction or target vessel revascularization associated with an index graft (MACE =0). At the time of follow-up, $68 \%$ of the patients were treated with aspirin only. In 91 implanted patients a stress ECG was performed, and 93.4\% $(\mathrm{n}=85)$ 


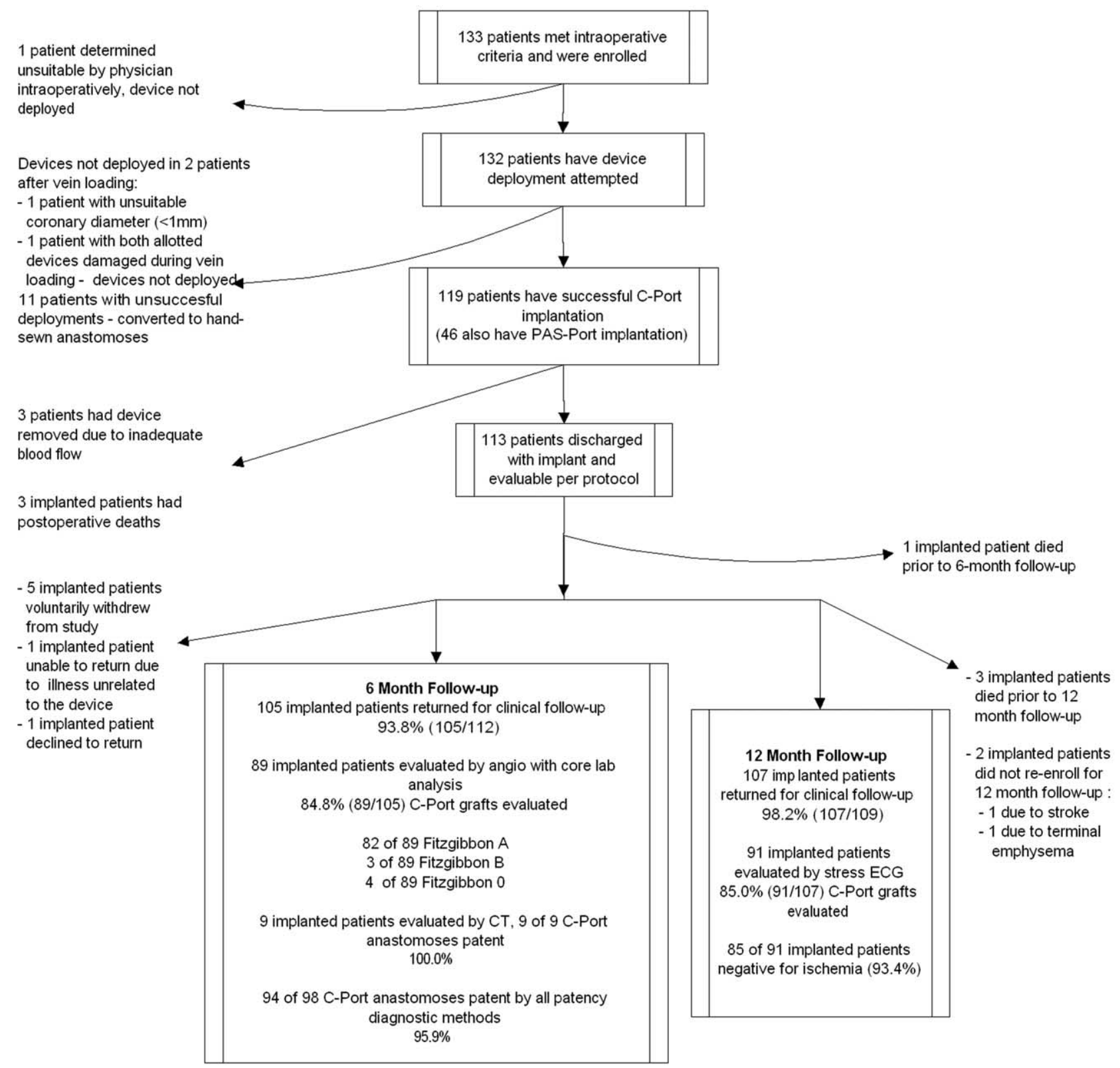

Figure 4. Patient flow chart. CT, Computed tomography; ECG, electrocardiography.

had no evidence of myocardial ischemia. This test had a positive result in 6 patients. In one patient the C-Port graft had been diagnosed to be occluded in the 6-month angiogram. In 3 patients additional angiograms were performed at 17 to 20 months postoperatively, which all showed the C-Port graft to be patent. The cause of the ischemia in one patient remained unclear, and in the remaining patient, the same pattern of ischemia had been detected in a 3-month stress ECG, and the index graft was found to be patent at 6 months. The 11 patients with unsuccessful deployments and
3 patients in whom the C-Port anastomoses had been converted to hand-sewn anastomoses because of poor blood flow (Figure 4) were also followed at 12 months postoperatively. Of these 14 patients, 1 patient died 4 months postoperatively because of recurrent strokes. The remaining 13 patients were well and without MACEs at 12 months.

\section{Discussion}

The potential advantages of using distal anastomotic devices are to rapidly and reliably produce a consistent con- 
TABLE 1. Baseline demographics and clinical characteristics

\begin{tabular}{|c|c|c|}
\hline Condition & $\begin{array}{l}\text { Enrolled patients } \\
\qquad(\mathrm{n}=133), \mathrm{n}\end{array}$ & $\begin{array}{l}\text { Evaluable patients } \\
\text { per protocol } \\
(n=113), n\end{array}$ \\
\hline Age $(y)$, mean $\pm S D$ & $68.5 \pm 7.7(133)$ & $68.6 \pm 8.0(113)$ \\
\hline Confidence interval & $67.2-69.8$ & $67.1-70.1$ \\
\hline Male sex & $111(83.5 \%)$ & $94(83.2 \%)$ \\
\hline History of smoking & $69(51.9 \%)$ & $57(50.4 \%)$ \\
\hline \multicolumn{3}{|l|}{ Family history of coronary } \\
\hline artery disease & $49 / 111(44.1 \%)$ & $41 / 98(41.8 \%)$ \\
\hline Diabetes & $48(36.1 \%)$ & $42(37.2 \%)$ \\
\hline Morbid obesity & $6(4.5 \%)$ & $5(4.4 \%)$ \\
\hline Hyperlipidemia & $105 / 131(80.2 \%)$ & $88 / 111(79.3 \%)$ \\
\hline Renal dysfunction & $0(0 \%)$ & $0(0 \%)$ \\
\hline \multicolumn{3}{|l|}{ Chronic obstructive } \\
\hline pulmonary disease & $18 / 129(14.0 \%)$ & $15 / 109(13.8 \%)$ \\
\hline \multicolumn{3}{|l|}{ Peripheral vascular } \\
\hline disease & $19(14.3 \%)$ & $15(13.3 \%)$ \\
\hline Hypertension & 108/132 (81.8\%) & $90 / 112(80.4 \%)$ \\
\hline Cerebrovascular accident & $4(3.0 \%)$ & $0(0 \%)$ \\
\hline Infectious endocarditis & $0(0 \%)$ & $0(0 \%)$ \\
\hline Hepatic failure & $4(3.0 \%)$ & $3(2.7 \%)$ \\
\hline \multicolumn{3}{|l|}{ Prior myocardial } \\
\hline infarction & $58(43.6 \%)$ & $49(43.4 \%)$ \\
\hline Angina & $117(88.0 \%)$ & $99(87.6 \%)$ \\
\hline Arrhythmia & $33(24.8 \%)$ & $26(23.0 \%)$ \\
\hline Congestive heart failure & $0(0 \%)$ & $0(0 \%)$ \\
\hline Bleeding disorder & $0(0 \%)$ & $0(0 \%)$ \\
\hline CCS class III or IV & $66(49.6 \%)$ & $52(46.1 \%)$ \\
\hline NYHA class III* & $51(38.4 \%)$ & $42(37.2 \%)$ \\
\hline \multicolumn{3}{|l|}{ No. of diseased vessels } \\
\hline Single & $3(2.3 \%)$ & $3(2.7 \%)$ \\
\hline Double & $40(30.1 \%)$ & $33(29.2 \%)$ \\
\hline Triple & $90(67.7 \%)$ & $77(68.1 \%)$ \\
\hline Left main disease & $19 / 132(14.4 \%)$ & $17 / 112(15.2 \%)$ \\
\hline $\begin{array}{c}\text { Ejection fraction }(\%), \\
\text { mean } \pm S D\end{array}$ & $59.4 \pm 12.6$ & $59.4 \pm 13.3(113)$ \\
\hline Confidence interval & $57.2-61.5$ & $57-61.9$ \\
\hline
\end{tabular}

$S D$, Standard deviation; CCS, Canadian Cardiovascular Society; NYHA, New York Heart Association. *New York Heart Association class IV was a preoperative exclusion criterion.

nection of bypass grafts to coronary arteries (Figure 5). This should be done in a standardized fashion and requires minimal training. Anastomotic devices must be designed to successfully cope with variations in patient anatomy and vascular disease. ${ }^{5}$ Finally, yet importantly, easy removal in the event of device malfunction should be possible. In this study we were able to demonstrate that the C-Port System favorably addresses the majority of these requirements.

Because of its novel design, the C-Port System is able to administer all functions necessary to create a compliant anastomosis in a single step. This makes rapid deployment possible. Its reliability, with 11 device malfunctions in 130 attempts (8.5\% failure rate), was satisfactory for a novel product, especially because all failed deployments were not technical but rather related to technique and vessel selection. Successful deployment with the C-Port System requires alignment of the cartridge bays with the anvil that has been placed inside the coronary artery. This can be achieved by means of dissection of the upper $50 \%$ of the circumference of the coronary artery or by avoiding intramural targets. If the cartridge cannot align with the anvil because of tissue interference, the staples will not form on the anvil, and the anastomosis will be incomplete. This was the cause for the majority of the failures observed and allowed easy conversion to a hand-sewn anastomosis. A second type of failure was related to the limitations of the arteriotomy knife to create an arteriotomy in target vessels with more than $0.75-\mathrm{mm}$ wall thickness. In these instances the anastomosis was removed, and the anvil insertion hole was extended to create an adequate arteriotomy for hand-sewn anastomoses.

Because of the design of the product, the distance between clips is marginally larger at the toe and heel. In many instances during this trial, additional conventional stitches were placed to achieve hemostasis. However, this limitation is offset by the ability to perform a consistent, reproducible, and compliant anastomosis on target vessels as small as $1 \mathrm{~mm}$ in diameter. Future product iterations will address this shortcoming.

In patients in whom the C-Port deployment was clinically unsuccessful, a safe bailout with conversion to a hand-sewn anastomosis was possible in all cases, without any compromise to patient long-term outcome. At the end of each procedure, the patient was informed of the success of the deployment, and many patients in whom the deployment was unsuccessful elected to refuse angiographic follow-up.

Any alternative technique used to construct a distal anastomosis in coronary surgery should provide patency similar to that obtained with conventional suturing techniques using the same type of graft. Mack and associates presented a meta-analysis at the Techno College, EACTS 2004 (European Association of Cardio-Thoracic Surgeons), comprising more than 28,000 grafts. According to these researchers, the patency of hand-sewn saphenous vein grafts can be expected to be $87.9 \%$ after 30 days, $84.1 \%$ between 3 and 6 months, $82.7 \%$ after 12 months, and $74.3 \%$ between 2 and 5 years. In this initial C-Port trial, graft patency (FitzGibbon $\mathrm{A}$ and $\mathrm{B}$ ) exceeded the meta-analysis benchmark, with discharge patency of $99 \%$ and 6-month patency of $95.9 \%$. Further evaluation of the C-Port grafts with significant stenosis or occlusion revealed that 5 of these 7 grafts were anastomosed to coronary arteries with a native stenosis of less than or equal to $60 \%$. According to Manninen and coworkers, ${ }^{6}$ reduced native artery stenosis is a predictor of graft occlusion caused by competitive flow. 


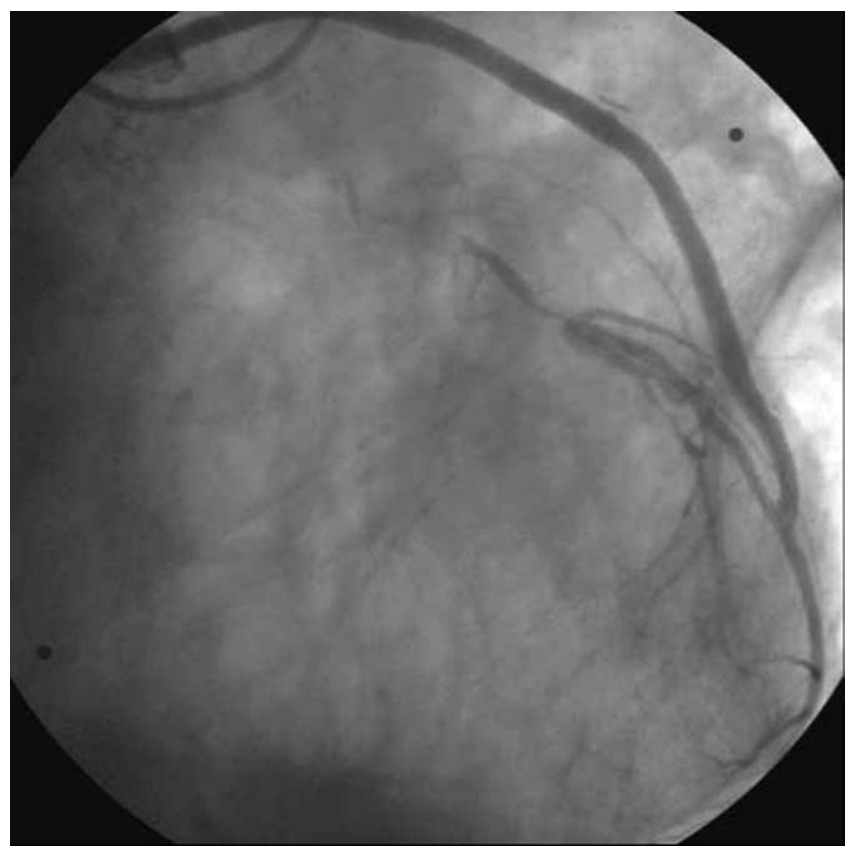

Figure 5. Six-month angiogram of a saphenous vein-to-obtuse marginal branch using the C-Port System.

The 12-month evaluation, including assessment by means of stress ECG and determination of MACEs, demonstrated a favorable outcome in patients after implantation of the C-Port System. None of the patients experienced a myocardial infarction or required a target vessel revascularization since discharge. The overall mortality since discharge (3.6\%) compares with published data by Cheng and colleagues ${ }^{7}$ and Unger and associates, ${ }^{8}$ who describe a 1 -year mortality of $2.6 \%$ and $3.6 \%$, respectively. In addition, Unger and associates found a myocardial infarction rate of $4.1 \%$ in more than 600 patients studied 1 year postoperatively.

The C-Port anastomosis system has some important characteristics that might help explain this favorable outcome. The attachment of the graft to the target vessel is accomplished with individual clips, which results in a compliant anastomosis. The vascular anastomosis originally developed by Alexis Carrel used a modified interrupted technique. Cardiac surgeons adopted this technique, and some of the pivotal studies describing long-term patency outcome in CABG surgery by Loop and coworkers ${ }^{9}$ and Lytle and colleagues $^{10}$ are based on the interrupted technique. Wolf and associates ${ }^{11}$ have recently published results from a clinical trial in which multiple clips were used to perform an interrupted anastomosis in the left internal thoracic arteryto-left anterior descending coronary artery bypass grafts. According to these authors, this technique avoided a stenosis of the anastomosis, which can amount to $24 \%$ in the hand-sewn continuous stitch technique. In addition to providing a compliant anastomosis, the C-Port System clips have a small amount of blood-exposed nonintimal surface (Figure 3). Scheltes and coworkers ${ }^{12}$ studied various anastomotic devices, compared them with sutured anastomoses, and postulated that a reduction in blood-exposed nonintimal surface would be beneficial for long-term outcome. The automated creation of the anastomosis ensures consistency from one anastomosis to another. Finally, the C-Port System allows placement of the distal anastomosis without interrupting native artery blood flow, thereby avoiding the need for intracoronary shunts or temporary myocardial ischemia.

Limitations of the study include a nonrandomized patient population selected for conformance with prespecified inclusion and exclusion criteria.

In summary, the 6-month patency rate and 12-month clinical outcome of the C-Port device is very promising. On the basis of these successful results, we have continued evaluation of this product in successive studies with longerterm follow-up. The integrated design of this product allows rapid and safe deployment and might prove to be a valuable asset in coronary surgery, especially in beating-heart procedures (off-pump coronary artery bypass).

\section{References}

1. Carrel A. La technique opératoire des anastomoses vasculaires et all-transplantations des viscères. Lyon Med. 1902;98:859-63.

2. Filsoufi F, Farivar RS, Aklog L, Anderson CA, Chen RH, Lichtenstein $\mathrm{S}$, et al. Automated distal coronary bypass with a novel magnetic coupler (MVP system). J Thorac Cardiovasc Surg. 2004;127:185-92.

3. FitzGibbon GM, Kafka HP, Leach AJ, Keon WJ, Hooper GD, Burton JR. Coronary bypass graft fate and patient outcome: angiographic follow-up of 5,065 grafts related to survival and reoperation in 1,388 patients during 25 years. J Am Coll Cardiol. 1996;28:616-26.

4. Caskey MP, Kirshner MS, Alderman EL, Hunsley SL, Daniel MA. Six-month angiographic evaluation of beating-heart coronary arterial graft interrupted anastomoses using the coalescent u-clip anastomotic device: a prospective clinical study. Heart Surg Forum. 2002;5: 319-26.

5. Carrel TP, Eckstein FS, Englberger L, Berdat PA, Schmidli J. Clinical experience with devices for facilitated anastomoses in coronary artery bypass surgery. Ann Thorac Surg. 2004;77:1110-20.

6. Manninen HI, Jaakkola P, Suhonen M, Rehnberg S, Vuorenniemi R, Matsi PJ. Angiographic predictors of graft patency and disease progression after coronary artery bypass grafting with arterial and venous grafts. Ann Thorac Surg. 1998;66:1289-94.

7. Cheng DC, Bainbrigde D, Martin JE, Novick, RJ. Does off-pump coronary artery bypass reduce mortality, morbidity, and resource utilization when compared with conventional coronary artery bypass? A meta-analysis of randomized trials. Anesthesiology. 2005;102:188203.

8. Unger F, Serruys PW, Yacoub M, Ilsley C, Paulsen PK, Nielsen TT, et al. Revascularization in multivessel disease: comparison between two-year outcomes of coronary bypass surgery and stenting. $J$ Thorac Cardiovasc Surg. 2003;125:809-20.

9. Loop FD, Lytle BW, Cosgrove DM, Stewart RW, Goormastic M, Williams GW, et al. Influence of the internal mammary artery graft on 10-year survival and other cardiac events. N Engl J Med. 1986;314: $1-6$.

10. Lytle BW, Loop FD, Cosgrove DM, Ratliff NB, Easley K, Taylor PC. Long-term ( 5 to 12 years) serial studies on internal mammary artery 
and saphenous vein coronary bypass grafts. J Thorac Cardiovasc Surg. 1985;89:248-58.

11. Wolf RK, Alderman EL, Caskey MP, Raczkowski AR, Dullum MK, Lundell DC, et al. Clinical and six month angiographic evaluation of coronary arterial graft interrupted anastomoses by use of a self-closing clip device: a multi-center prospective clinical trial. $J$ Thorac Cardiovasc Surg. 2003;126:168-78.

12. Scheltes JS, van Andel CJ, Pistecky PV, Borst C. Coronary anastomotic devices: blood-exposed non-intimal surface and coronary wall stress. J Thorac Cardiovasc Surg. 2003;126:191-9.

\section{Discussion}

Dr Pascal A. Berdat (Berne, Switzerland). Some years ago, the development of devices to facilitate and accelerate vascular connections in CABG surgery was thought to revolutionize the procedure and to induce a beneficial effect on the adoption of beatingheart and even endoscopic bypass surgery. Demertzis and colleagues present early angiographic and clinical results obtained in distal coronary anastomosis by using the Cardica C-Port device. This system has truly some advantages over other devices seen in the past: the size of the target vessel can be as small as 1 to 1.5 $\mathrm{mm}$; the sequence of performing the distal anastomosis first or last is up to the surgeon; and most important, the anastomosis is pulsatile and compliant.

With this study, the authors demonstrate good safety and efficacy of this novel technology and have to be congratulated for their excellent results. Efficacy in this context involves both successful application of the device and creation of the patent anastomosis. Because this is a feasibility trial with an intention-to-treat model, the success rate of delivering the system was a fair $85 \%$ because it was successfully applied in 116 of 133 patients initially enrolled. In 11 patients conversion to a hand-sewn anastomosis was necessary; in 3 patients poor blood flow across the graft also made the redo of the anastomosis by hand necessary; 2 other patients were deemed unsuitable for the use of the device; and finally, in another patient the device failed because of a technical problem.

What about efficacy in terms of creation of a patent anastomosis? Although not all patients were followed up by means of angiography or CT, patency rates were excellent, with a FitzGibbon A rating at discharge of $96 \%$ and $93 \%$ after 6 months. Given the fact that all these grafts were veins and the target vessels were mainly branches of the circumflex, the diagonal, or the right coronary arteries, this is a very good result. However, more detailed information on how these anastomoses looked should be provided. I believe that classifying these anastomoses into FitzGibbon scores is not precise enough, and the anastomoses should be better characterized. Can you comment on this?
Dr Demertzis. Yes. I would like to address the issue of efficacy first. You mentioned the 11 unsuccessful deployments. The unsuccessful deployments were due to the fact that the cartridge has to align with the anvil and the tissue around the coronary artery has to be dissected to a sufficient amount. If this is not the case, the clips could miss the anvil and not deform, leading to a clinically unsuccessful anastomosis. This is not a true failure. It is a technique failure and not a technical failure.

The other reason to have a clinically unsuccessful deployment is if you do not respect the specs on the wall thickness of the target vessel. Therefore in a target vessel that is heavily diseased and thickened, you can have an unsuccessful deployment. This was the case in the initial phase of the study. As we understood the reasons for that and applied these criteria to our target vessels, this problem dissolved. At the end of this study and later on during the C-Port's commercial use, this problem has actually disappeared.

With regard to the FitzGibbon classification, we do have a complete quantitative graft and anastomosis analysis for every graft in every single patient, very precise and exact. Of course, with the FitzGibbon's classification, he have a rough way to group the grafts, and this is why it is widely used in the literature. Therefore for the sake of comparison, I think it is a rather adequate solution.

Dr Berdat. The use of this device seems rather safe, but there are some technical particularities. The extensive preparation of the vessel with dissection of $50 \%$ of the circumference and the need for creation of a separate incision and insertion of this device is not what could be called a no-touch technique. Furthermore, additional stitches precisely at the most sensitive points of the anastomoses, at the toe and heel, were usually necessary in this series. Can you comment on this?

Dr Demertzis. It was not intended to have a coronary anastomosis by not touching the coronary artery, of course.

The point on the stitches, yes, I have to mention that the tacking stitches were really superficial adventitial stitches and not transmural, which were absolutely sufficient in all the cases. You have to deal with the anvil insertion hole, which is somewhere around $1 \mathrm{~mm}$ behind the heel of the anastomosis. Quantitative analysis on the postoperative angiographs at discharge and at 6 months postoperatively did not reveal any problem in respect to that issue. Therefore it is a theoretic concern, but in real-world practice, it did not have any effect.

Dr Berdat. Again, the authors have to be congratulated to put their efforts in a field that has turned out to be controversial most recently. 